\title{
Multi-stimuli-triggered shape transformation of polymeric filaments derived from dynamic covalent block copolymers
}

Guang Yang, ${ }^{*} \dagger, \star$ Jie Wang,${ }^{\dagger}$ Yangyang Yan, ${ }^{\dagger}$ Zijuan Hai, ${ }^{\|}$Zan Hua ${ }^{\dagger}$ Guosong Chen $^{*}, \dagger$ ${ }^{\dagger}$ Biomass Molecular Engineering Center and Department of Materials Science and Engineering, School of Forestry and Landscape Architecture, Anhui Agricultural University, Hefei, Anhui 230036, China

The State Key Laboratory of Molecular Engineering of Polymers and Department of Macromolecular Science, Fudan University, Shanghai 200433, P. R. China

"Institutes of Physical Science and Information Technology, Anhui University, Hefei, Anhui 230601, China

Email: *guangyang@ahau.edu.cn

*guosong@fudan.edu.cn 


\section{Table of Contents}

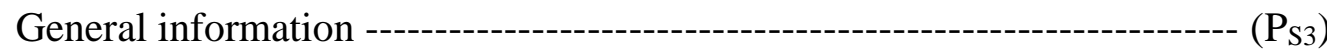

Synthetic procedures of small molecules and polymers ---------------------( $\left.\mathrm{P}_{\mathrm{S} 4-\mathrm{S} 5}\right)$

Characterization of PVEG and PVEG-PVEA in aqueous solution -------- --( $\left.\mathrm{P}_{\mathrm{S6-S12}}\right)$

Characterization of PVEG5-PVEA and Pman-PVEA in aqueous solution --( $\left.\mathrm{P}_{\mathrm{S} 13-\mathrm{S} 14}\right)$

The binding between ConA and glyco-nanopaticles from Pman-PVEA ----( $\left.\mathrm{P}_{\mathrm{S} 15}\right)$

Characterization of all synthetic compounds ------------------------------------(Ps $16-19)$

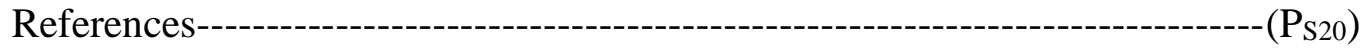




\section{Experimental section}

Materials. The chemicals including 4-(chloromethyl)styrene ( $>90 \%$, TCI), diethylamine ( $>98 \%, \mathrm{~J} \& \mathrm{~K})$, terephthalaldehyde mono(diethyl acetal) (>97\%, TCI), methyltriphenylphosphonium bromide (>98\%, TCI), n-BuLi (1.6 M in hexane, TCI), potassium carbonate $\left(\mathrm{K}_{2} \mathrm{CO}_{3},>98 \%\right.$, Guoyao), N,N-Dimethylformamide (DMF, analytical reagent, Guoyao), 2-Butanone (analytical reagent, Guoyao), phosphate buffer saline (PBS, J\&K), diethyl ether (analytical reagent, Guoyao), ethyl acetate (analytical reagent, Guoyao), deuterated chloroform $\left(\mathrm{CDCl}_{3}\right.$, containing $1 \mathrm{wt} \% \mathrm{TMS}$, 99.6 atom $\% \mathrm{D}$, Innochem) were used as purchased. The initiator of 2, 2'-azobis(isobutyronitrile) (AIBN, $>98 \%, \mathrm{~J} \& \mathrm{~K}$ ) was recrystallized from alcohol before use. Tetrahydrofuran (THF, analytical reagent, Guoyao) were distilled before use. All the other chemical reagents were used as purchased. Deionized water was used in this study. 


\section{Synthetic scheme}

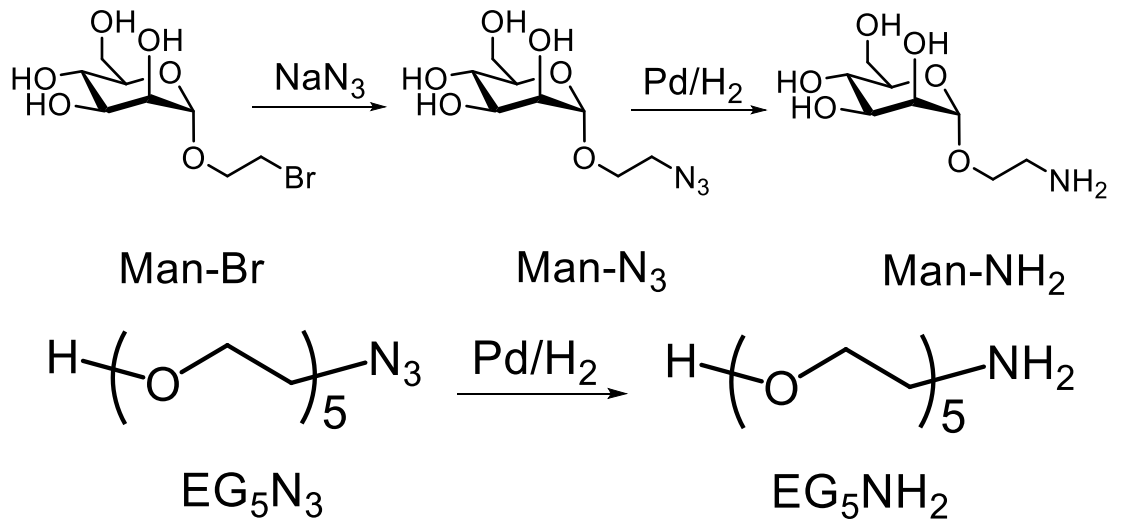

Scheme S1. Synthetic routes of Man-NH2 and EG5 $\mathbf{N H}_{2}$

\section{The synthesis of Man- $\mathrm{NH}_{2}$}

Man-Br was synthesized according to our previous work ${ }^{1}$. $1 \mathrm{~g}$ Man-Br (3.5 mmol) and $1 \mathrm{~g} \mathrm{NaN}_{3}(15.4 \mathrm{~mol})$ and $7 \mathrm{mg}$ tetramethylammonium iodide $(0.035 \mathrm{mmol})$ were added into $20 \mathrm{~mL}$ DMF. Then, the solution was heated at $65^{\circ} \mathrm{C}$ for $18 \mathrm{~h}$. The pure Man$\mathbf{N}_{3}(0.74 \mathrm{~g}$, yield: $85 \%)$ were obtained by the chromatography column using the mixture methanol and DCM (volume 1:8) as eluting agent. ${ }^{1} \mathrm{H}$ NMR (400 MHz, CD ${ }_{3} \mathrm{OD}, 298$ K, Figure S28) $\delta$ 4.84-4.83 (d, 1H), 3.96-3.91 (m, 1H), 3.88-3.85 (m, 2H), 3.76-3.71 (m, 2H), 3.68-3.57 (m, 3H), 3.45-3.42 (m, 2H). ${ }^{13} \mathrm{C}$ NMR (100 MHz, CD 3 OD, $298 \mathrm{~K}$, Figure S29) $\delta 100.38,73.47,71.08,70.64,67.12,66.30,61.50,50.34$. The all Man-N3 and $100 \mathrm{mg} 10 \%$ palladium on carbon were added into $25 \mathrm{~mL}$ methanol under $\mathrm{H}_{2}$ for 6 $\mathrm{h}$, after that, the palladium on carbon were filtered off and the solvent were evaporated leaving Man-NH2 0.6 g (yield: 91\%). ${ }^{1} \mathrm{H}$ NMR (400 MHz, CD ${ }_{3} \mathrm{OD}, 298 \mathrm{~K}$, Figure S30) $\delta 4.80(\mathrm{~d}, 1 \mathrm{H}), 3.88-3.84(\mathrm{~m}, 2 \mathrm{H}), 3.82-3.71(\mathrm{~m}, 3 \mathrm{H}), 3.66-3.61(\mathrm{~m}, 1 \mathrm{H}), 3.58-3.46(\mathrm{~m}$, 2H), 2.86-2.83 (m, 2H). ${ }^{13} \mathrm{C}$ NMR (100 MHz, CD ${ }_{3} \mathrm{OD}, 298 \mathrm{~K}$, Figure S31) $\delta 100.35$, $73.33,71.20,70.67,68.59,67.22,61.52,40.67$

\section{Synthesis of EG5 $\mathrm{NH}_{2}$.}

$\mathbf{E G}_{5} \mathbf{N}_{3}$ was synthesized according to our previous work ${ }^{2} .0 .5 \mathrm{~g}(1.9 \mathrm{mmol}) \mathbf{E G}_{5} \mathbf{N}_{3}$ and $120 \mathrm{mg} \mathrm{10 \%}$ palladium on carbon were added into $25 \mathrm{~mL}$ methanol under $\mathrm{H}_{2}$ for $6 \mathrm{~h}$, after that, the palladium on carbon were filtered off and the solvent were evaporated leaving EG5NH2 $0.4 \mathrm{~g}$ (yield:89\%). ${ }^{1} \mathrm{H}$ NMR (400 MHz, $\mathrm{CD}_{3} \mathrm{OD}, 298 \mathrm{~K}$, Figure S32) $\delta 3.73(\mathrm{~m}, 14), 3.64-3.62(\mathrm{~m}, 2 \mathrm{H}), 3.58-3.56(\mathrm{t}, 2 \mathrm{H}), 2.81-2.79(\mathrm{t}, 2 \mathrm{H})$. 
The synthesis of chain transfer agent $\mathrm{C}_{2}$-CTA. $\mathrm{C}_{2}$-CTA was synthesized following the similar procedures described in the literature ${ }^{3}$.

EGNHNH$_{2}$ was synthesized following the similar procedures described in the literature ${ }^{4} .{ }^{1} \mathrm{H}$ NMR (400 MHz, $\mathrm{CDCl}_{3}, 298 \mathrm{~K}$, Figure S33) $\delta 4.09$ (s, 1H), 3.68-3.63 (m, 46H), 3.55-3.53 (m, 2H), 3.37 (s, 1H). ${ }^{13} \mathrm{C}$ NMR (400 MHz, $\mathrm{CDCl}_{3}, 298 \mathrm{~K}$, Figure S34) $\delta 169.51,71.97,71.31,70.60,70.58,70.54,70.52,70.50,70.49,70.46,70.38$, 70.09 .

The synthesis of $N$-(4-vinylbenzyl)- $N, N$-diethylamine (VEA). VEA was synthesized according to the literature $5.7 .5 \mathrm{~g}$ (49mmol) 4-(chloromethyl) styrene, $5.4 \mathrm{~g}$ (49 mmol) diethylamine hydrochloride and $13.5 \mathrm{~g}(98 \mathrm{mmol}) \mathrm{K}_{2} \mathrm{CO}_{3}$ were added into $100 \mathrm{~mL}$ alcohol. The solution was kept at $50{ }^{\circ} \mathrm{C}$ for $24 \mathrm{~h}$ under nitrogen atmosphere. After evaporating the solvents, the compound VEA was purified by the chromatography column using the mixture ethyl acetate and petroleum ether (volume 1:2) as eluting agent. The final product as yellow oil was $7 \mathrm{~g}(75 \%)$. ${ }^{1} \mathrm{H} \mathrm{NMR}\left(400 \mathrm{MHz}, \mathrm{CDCl}_{3}, 298\right.$ K) $\delta$ 7.39-7.30 (m, 4H), 6.77-6.70 (m, 1H), 5.77-5.73 (m, 1H), 5.25-5.22 (m, 1H), 3.58 (s, 2H), 2.57-2.52 (m, 4H), 1.08-1.05 (t, 6H).

\section{The synthesis of PVEG was similar with PVEG-PVEA.}




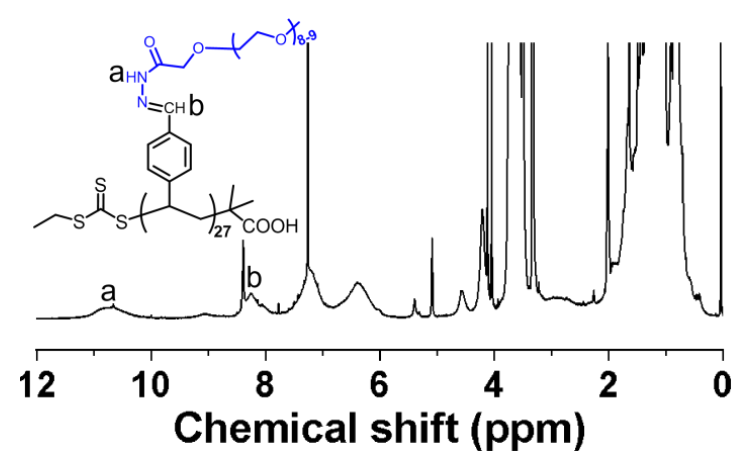

Figure S1. ${ }^{1} \mathrm{H}$ NMR spectrum of PVEG in $\mathrm{CDCl}_{3}$.

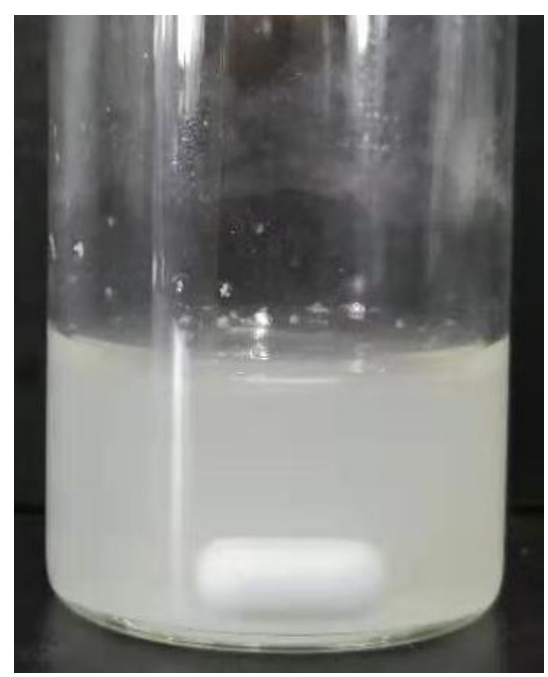

Figure S2. Photograph of PVEG-PVEA $(0.2 \mathrm{mg} / \mathrm{mL})$ in water.

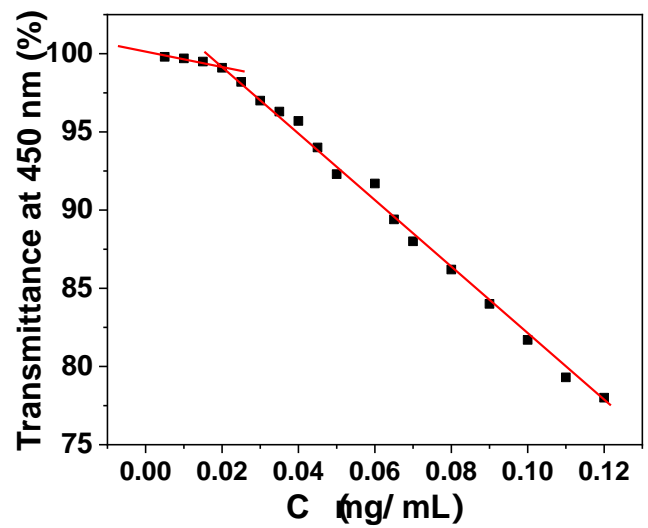

Figure S3. Optical transmittance versus concentration of PVEG-PVEA in aqueous solution. 


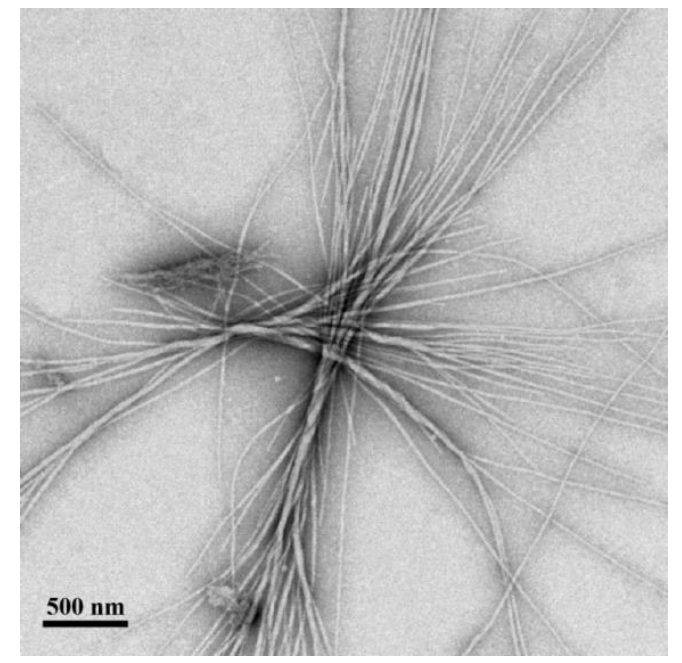

Figure S4. TEM image of PVEG-PVEA in water.

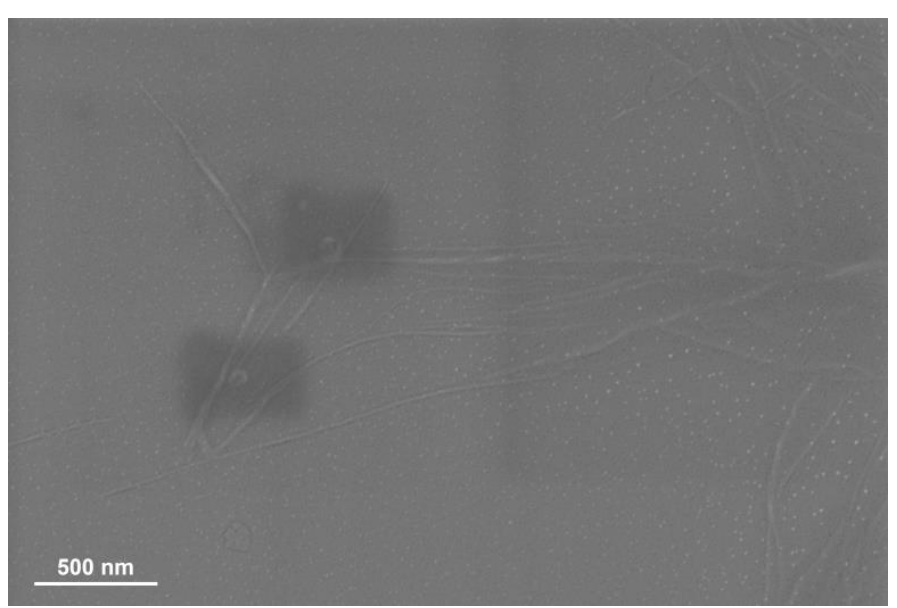

Figure S5. SEM image of PVEG-PVEA in aqueous solution.

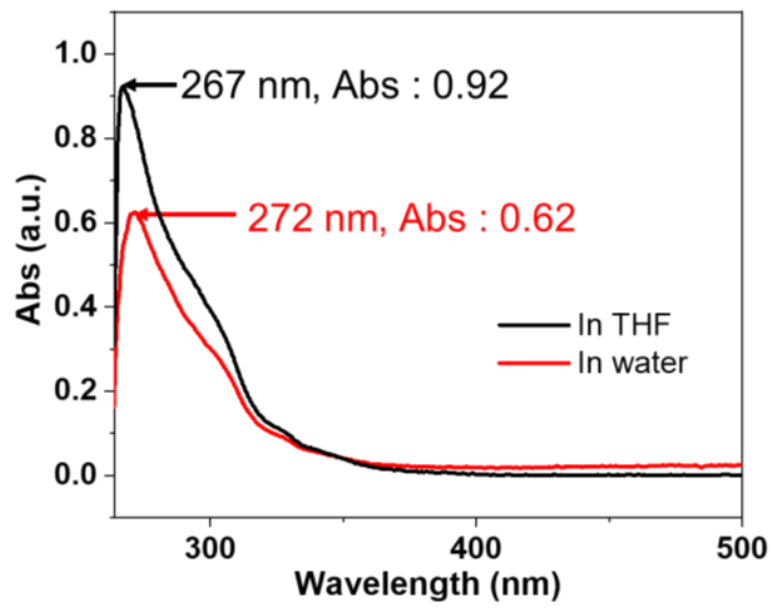

Figure S6. UV-vis spectra of PVEG-PVEA $(0.05 \mathrm{mg} / \mathrm{mL})$ in THF (black line) and water (red line). 

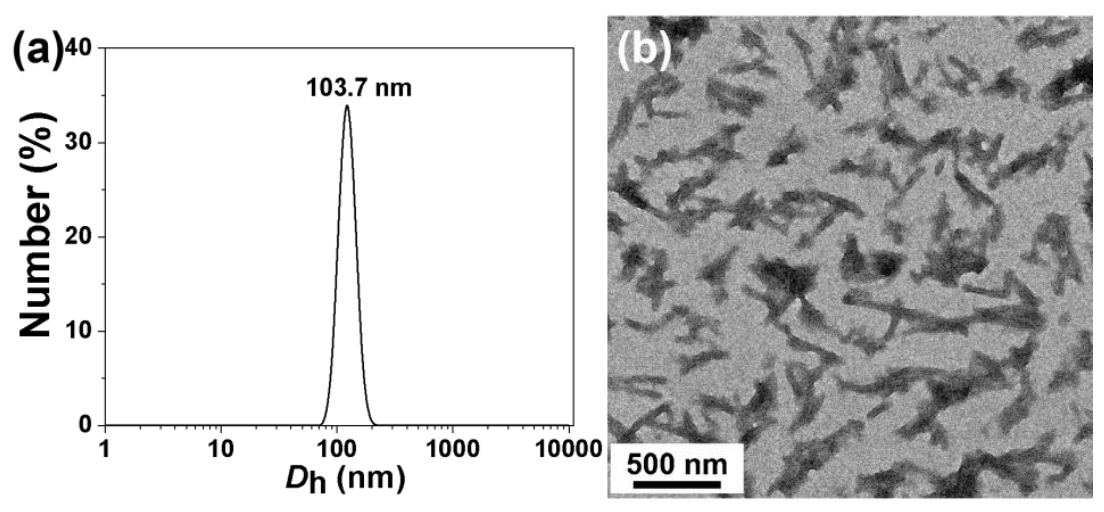

Figure S7. Characterization of PVEG $(0.2 \mathrm{mg} / \mathrm{mL})$ in aqueous solution: (a) DLS results and (b) TEM image.

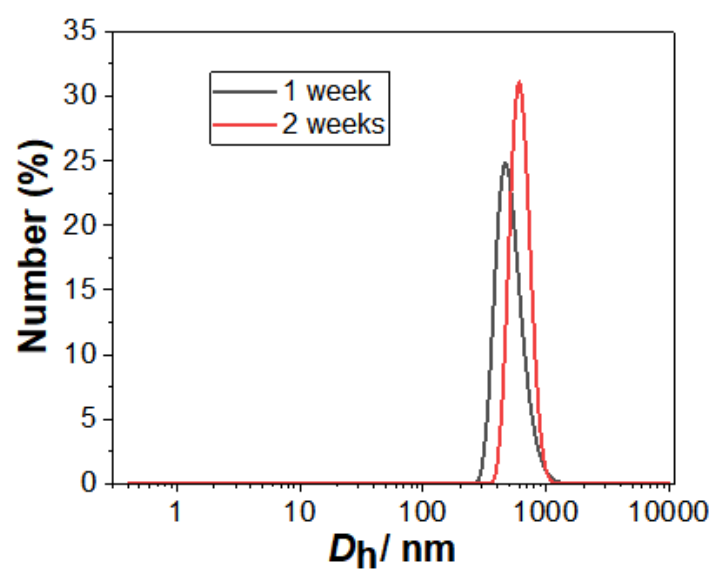

Figure S8. DLS analysis of PVEG-PVEA aggregates with standing time increasing: one week (black line) and two weeks (red line).

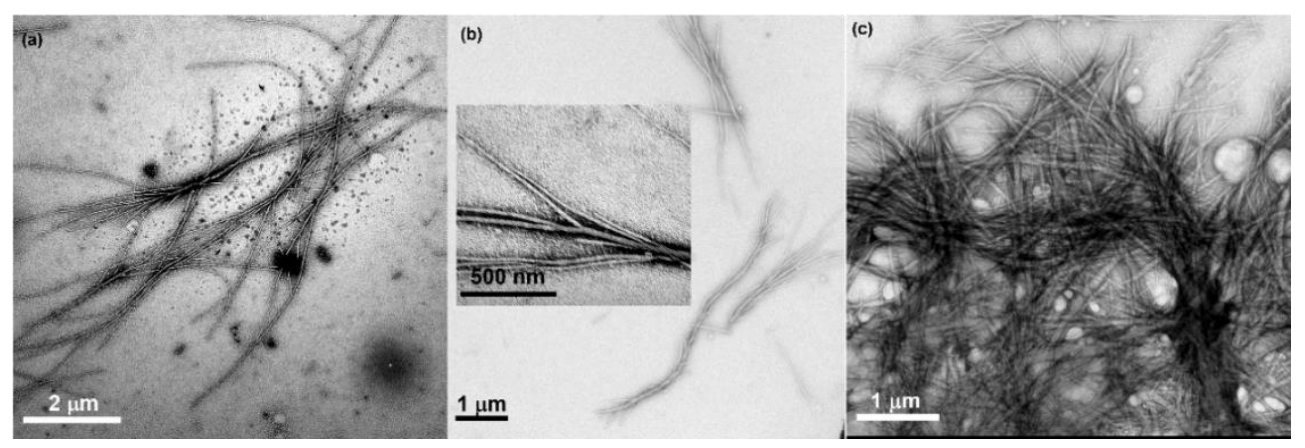

Figure S9. TEM images of PVEG-PVEA after standing different time at room temperature: (a) 1 week, (b) 3 weeks and (c) 1 month. 


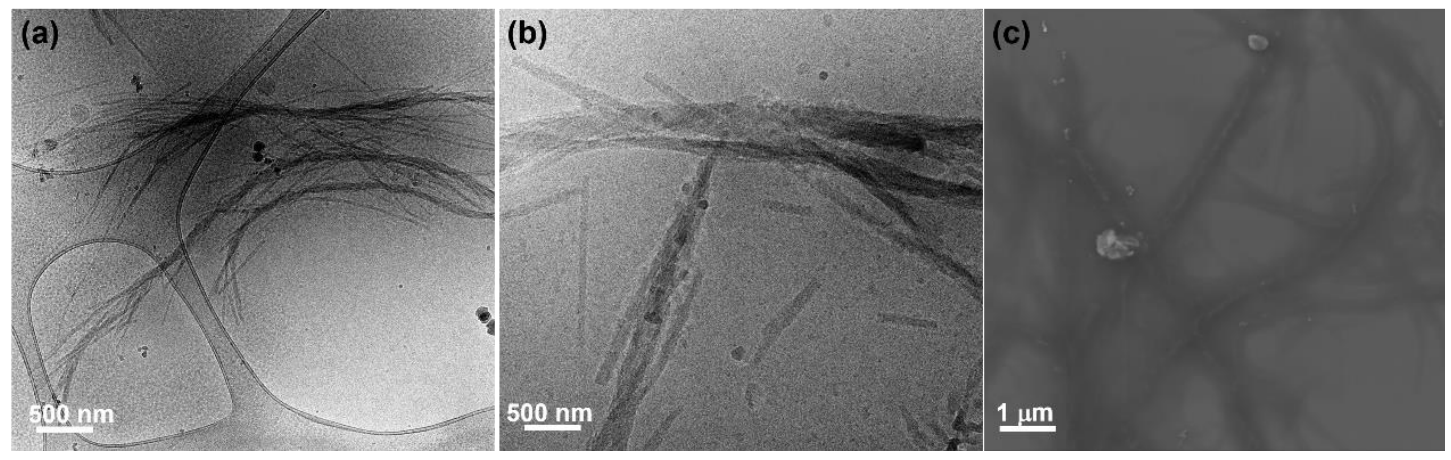

Figure S10. Cryo-TEM images of PVEG-PVEA after standing different time at room temperature: (a) 3 weeks and (b) 1 month. (c) SEM image after standing 1 month.

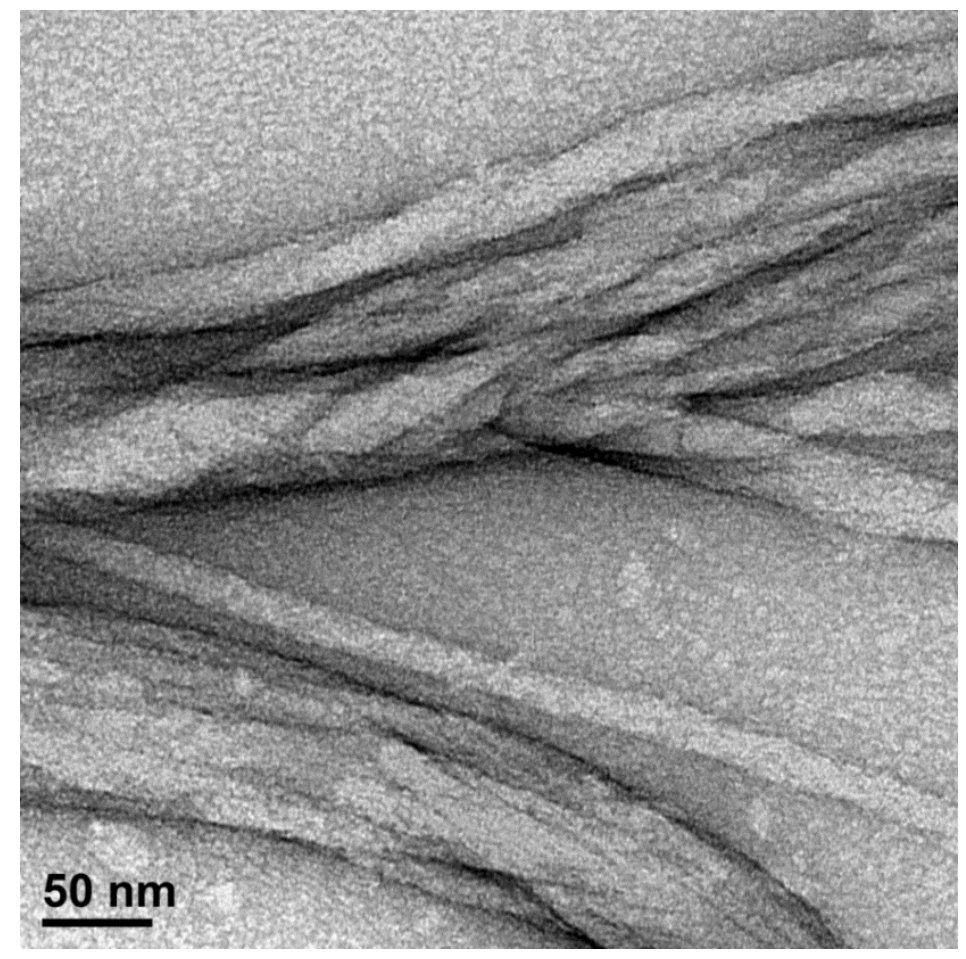

Figure S11. TEM image of PVEG-PVEA after standing 3 months at room temperature. 


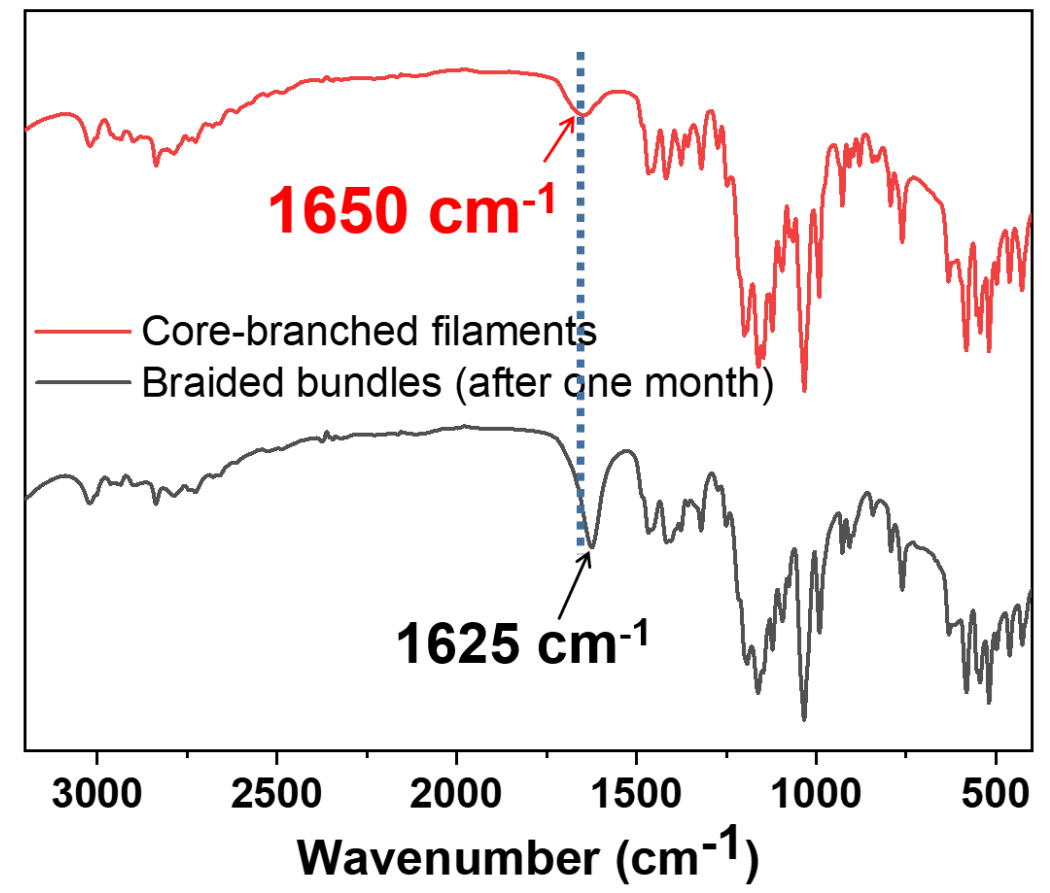

Figure S12. FT-IR spectra of the core-branched filaments (red line) and the braided bundles (after one months, black line) of PVEG-PVEA.

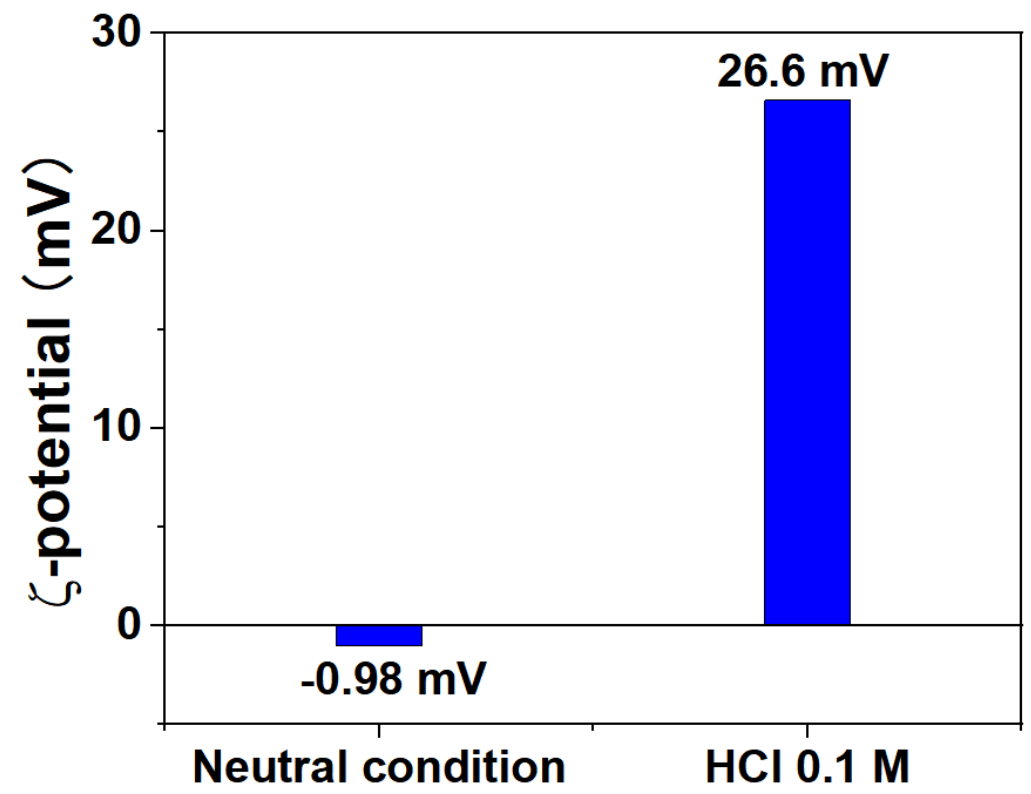

Figure S13. $\zeta$-potential value of PVEG-PVEA in water before $(-0.98 \mathrm{mV})$ and after $(26.6 \mathrm{mV})$ adding $\mathrm{HCl}$. 


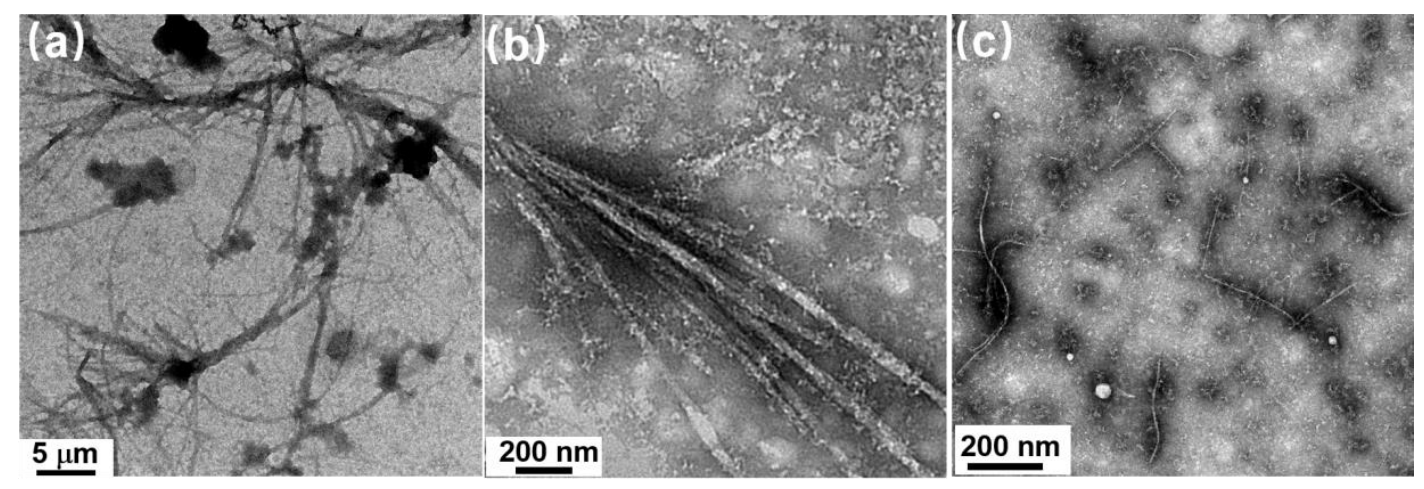

Figure S14. TEM images of PVEG-PVEA aggregates at different standing time after adding $\mathrm{HCl}$ : $5 \min (\mathrm{a}), 2 \mathrm{~h}(\mathrm{~b})$ and $5 \mathrm{~h}(\mathrm{c})$.

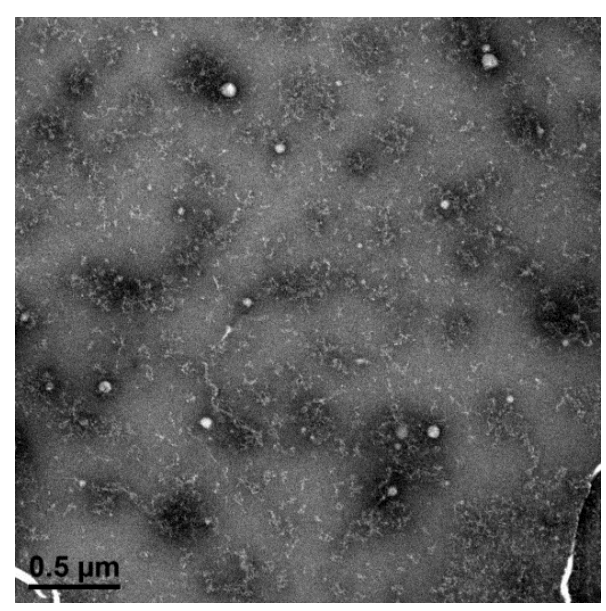

Figure S15. TEM image of PVEG-PVEA after the addition of $\mathrm{HCl}$ for one day.

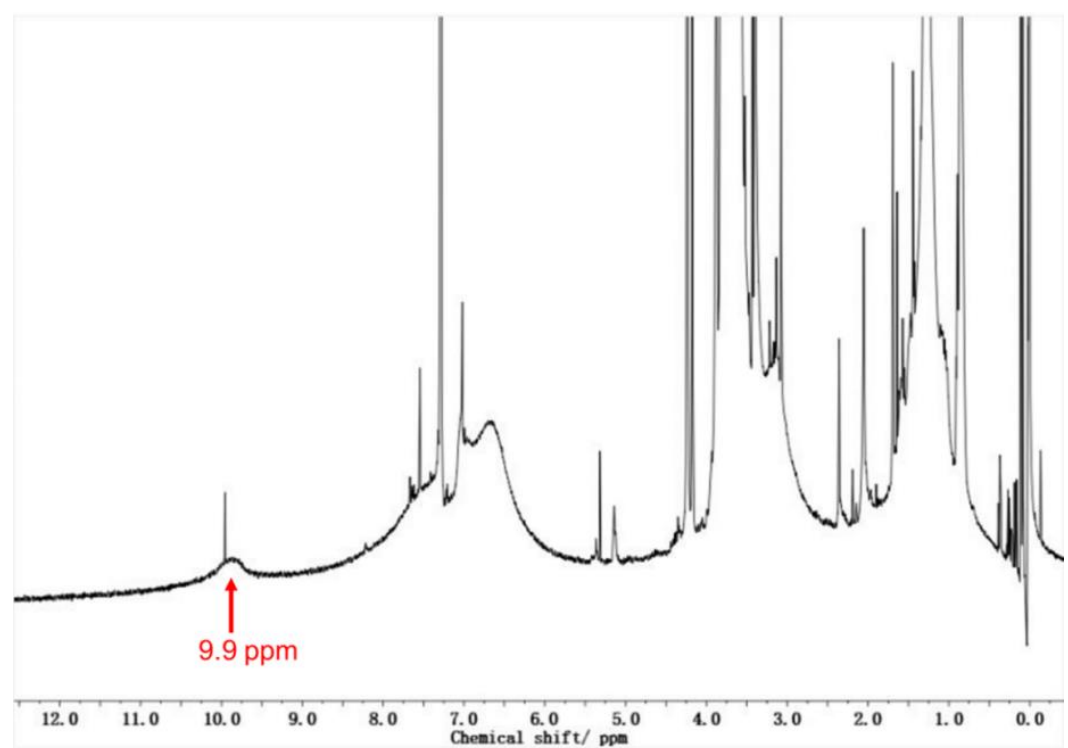

Figure S16. ${ }^{1} \mathrm{H}$ NMR spectrum of PVEG-PVEA after the addition of $\mathrm{HCl}$ for $7 \mathrm{~h}$. 


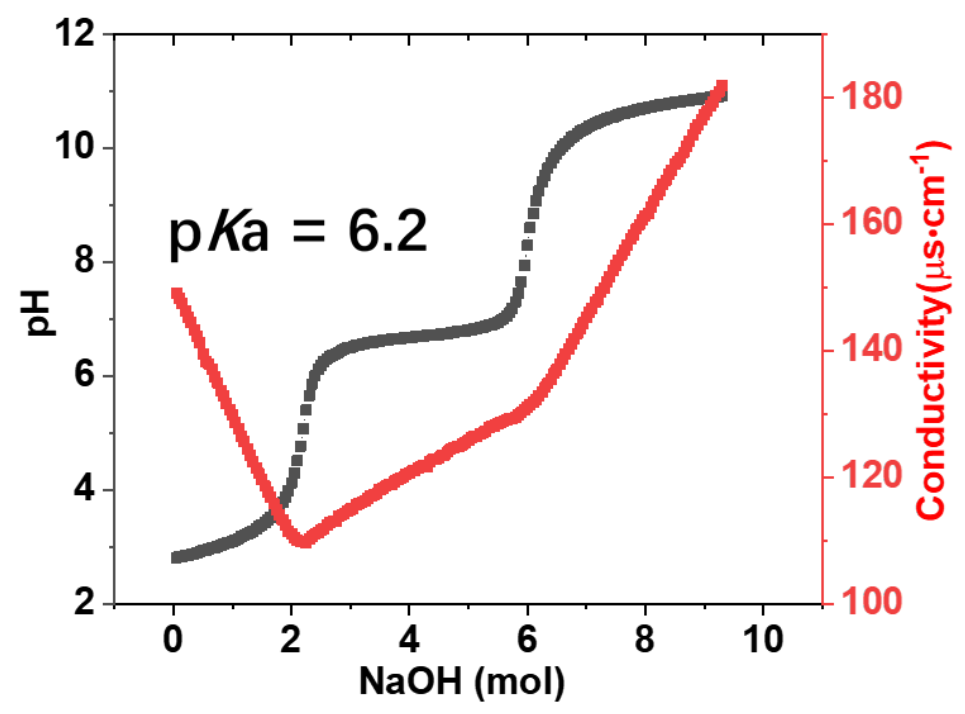

Figure S17. The variation of conductivity and $\mathrm{pH}$ of $\mathrm{PVEA}_{17}$ in water $(3 \mathrm{mg} / \mathrm{mL})$ during adding $\mathrm{NaOH}(0.05 \mathrm{mM})$ to the solution.
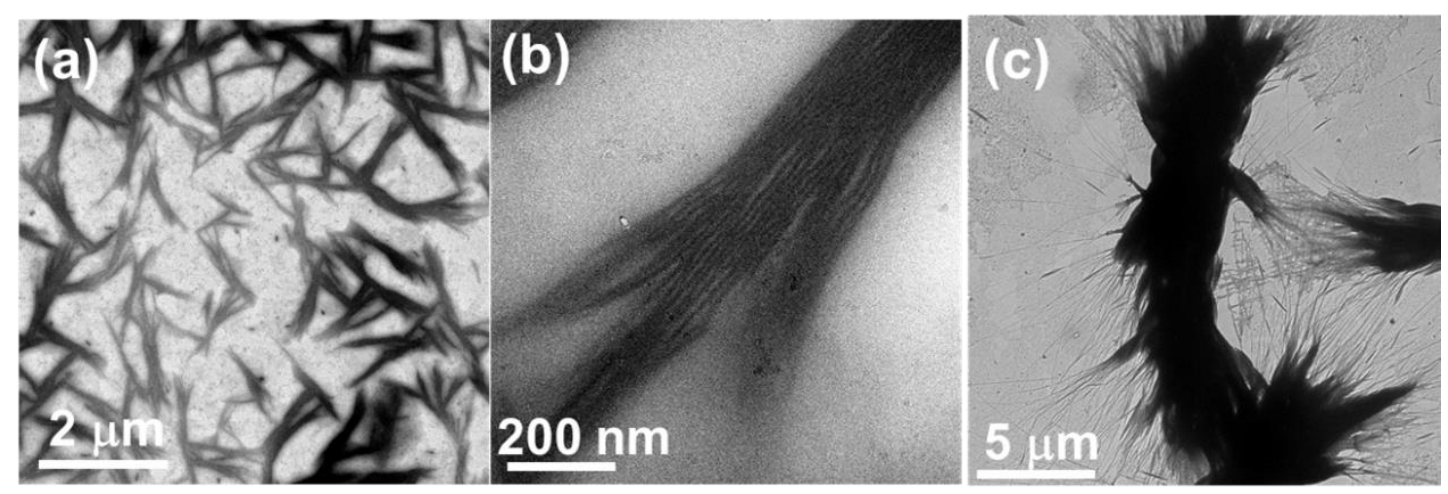

Figure S18. TEM images of PVEG-PVEA aggregates at different standing time after adding $\mathrm{NaOH}: 10$ min (a) and (b), 2h (c).

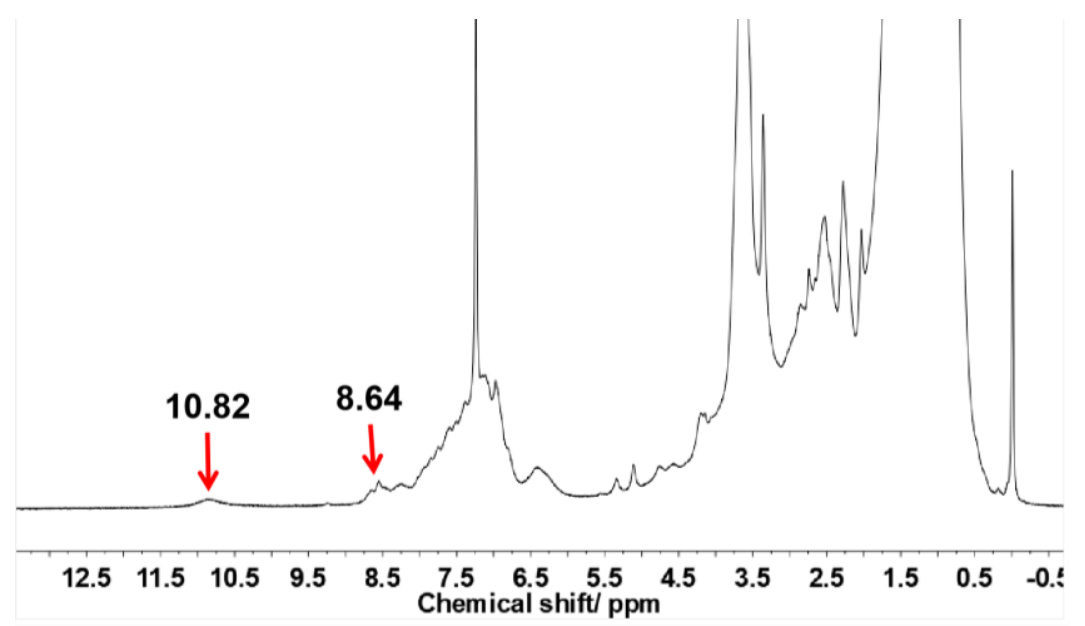

Figure S19. ${ }^{1} \mathrm{H}$ NMR spectrum of PVEG-PVEA after the addition of $\mathrm{NaOH}$. 


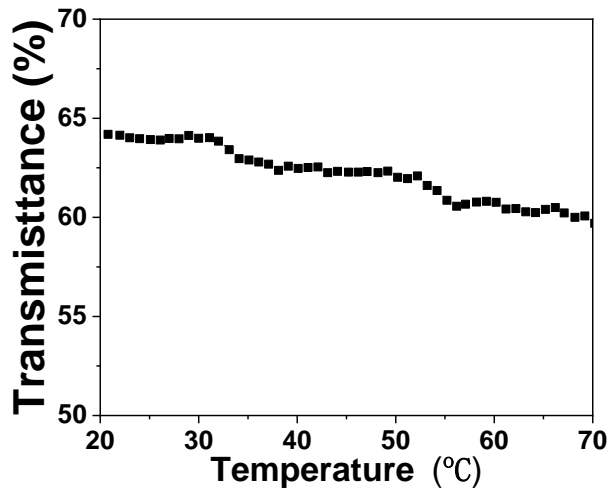

Figure S20. Optical transmittance of PVEG-PVEA in water as a function of temperature from 20 to $70^{\circ} \mathrm{C}$.

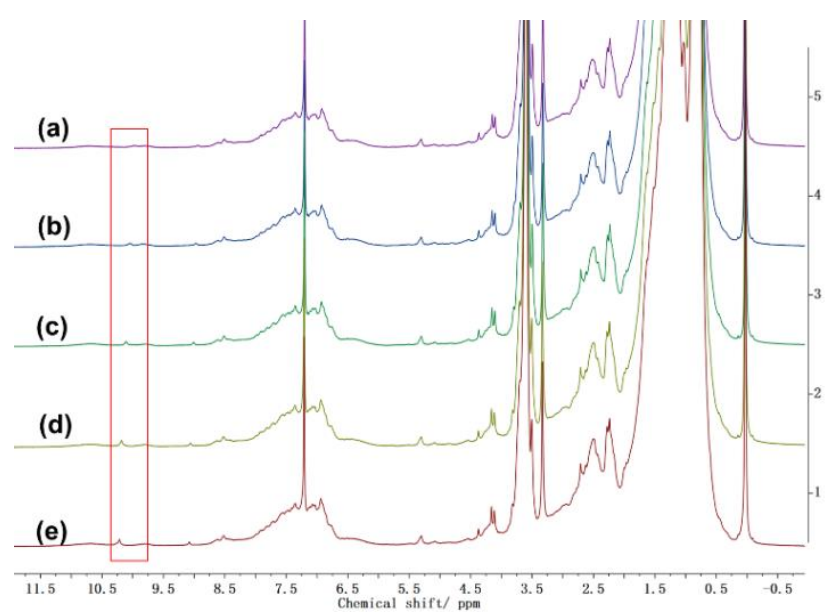

Figure S21. Variable temperature ${ }^{1} \mathrm{H}$ NMR of PVEG-PVEA in $\mathrm{CDCl}_{3}$ : (a) $40{ }^{\circ} \mathrm{C}$, (b) $45^{\circ} \mathrm{C}$, (c) $50{ }^{\circ} \mathrm{C}$, (d) $55^{\circ} \mathrm{C}$ and (e) $60{ }^{\circ} \mathrm{C}$.

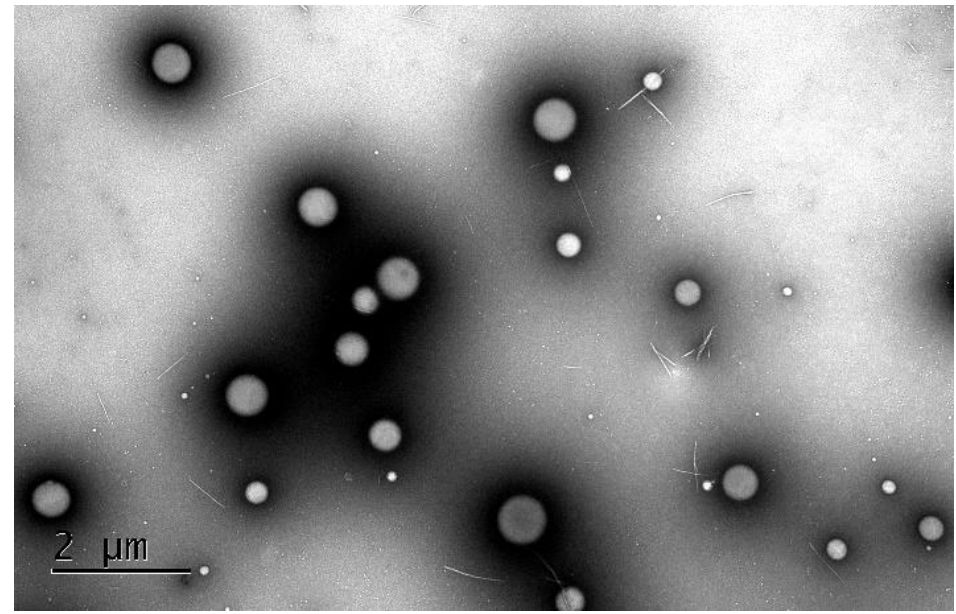

Figure S22. TEM image of PVEG-PVEA after lowering the temperature $\left(60^{\circ} \mathrm{C}\right)$ to room temperature for 1 day. 


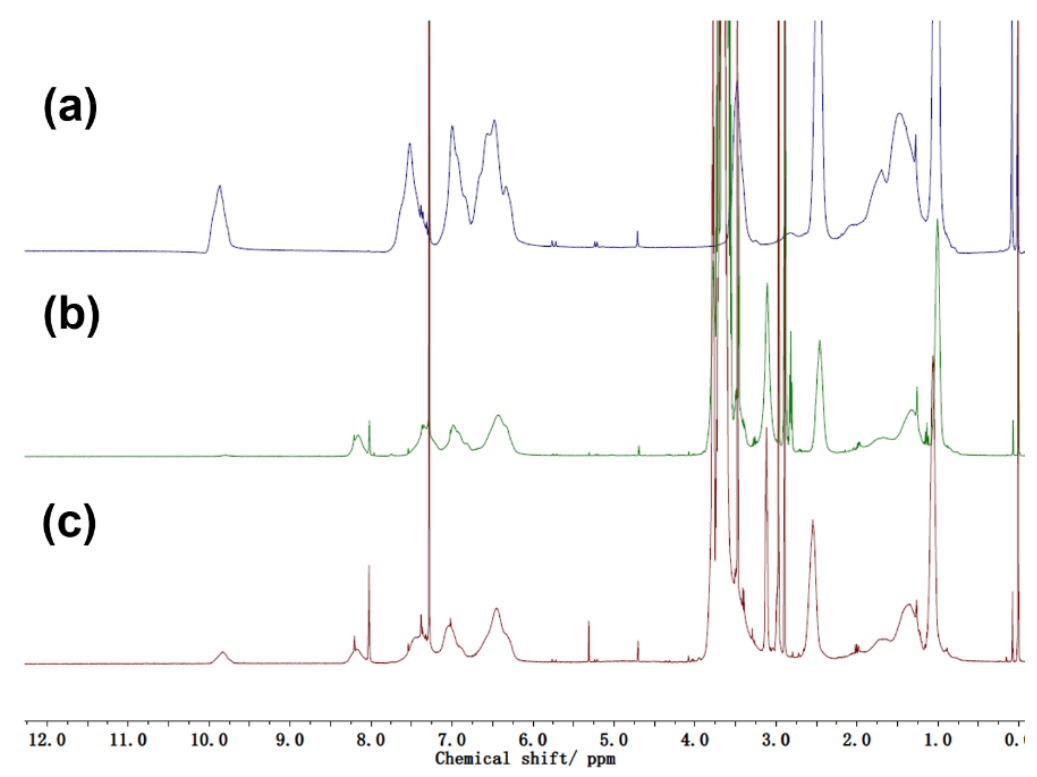

Figure S23. ${ }^{1} \mathrm{H}$ NMR spectra in $\mathrm{CDCl}_{3}$ : (a) PVBA-PVEA, (b) The mixture PVBAPVEA and EG5 $\mathbf{N H}_{2}$, (c) After the addition of DCl into mixture PVBA-PVEA and EG5NH2.

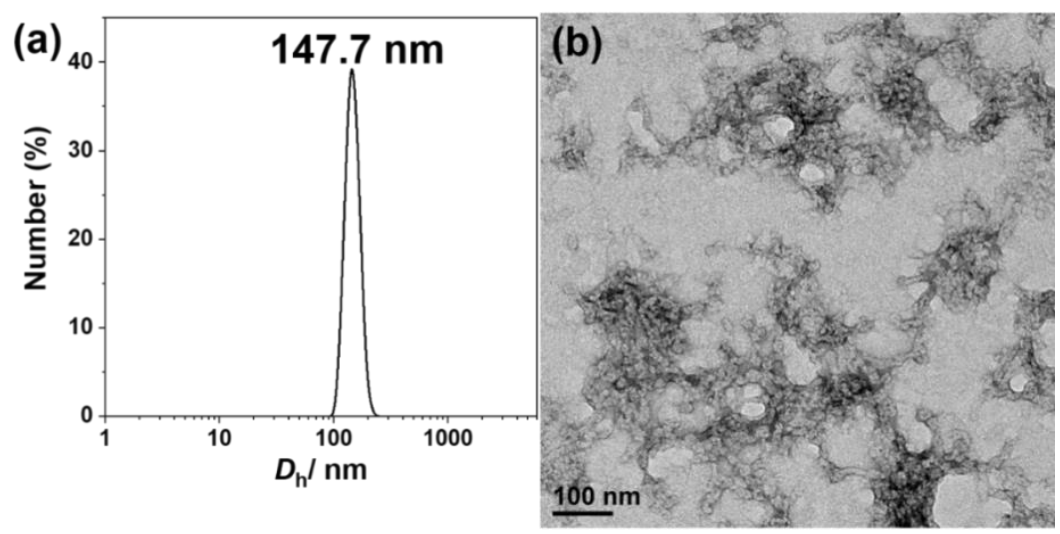

Figure S24. Characterization of $\mathrm{PVEG}_{5}-\mathrm{PVEA}$ after the addition of $\mathrm{NaOH}$ for $10 \mathrm{~min}$ (a) DLS analysis and (b) TEM image. 


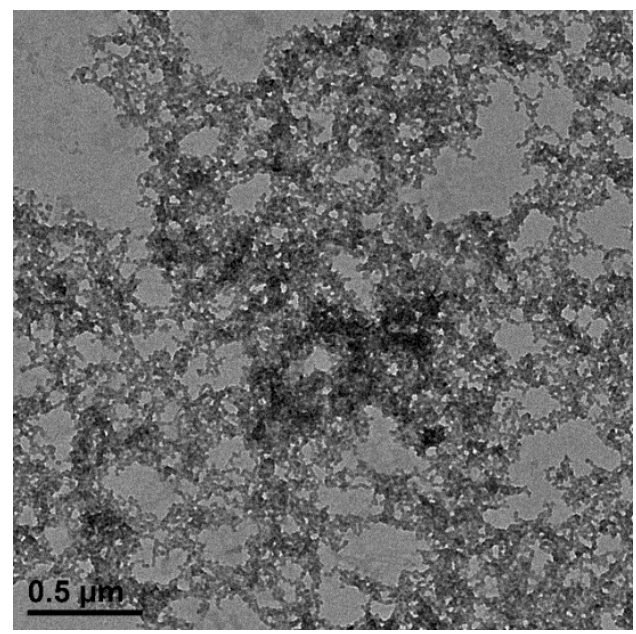

Figure S25. TEM image of PVEG5-PVEA after the addition of $\mathrm{NaOH}$ for $1 \mathrm{~h}$.

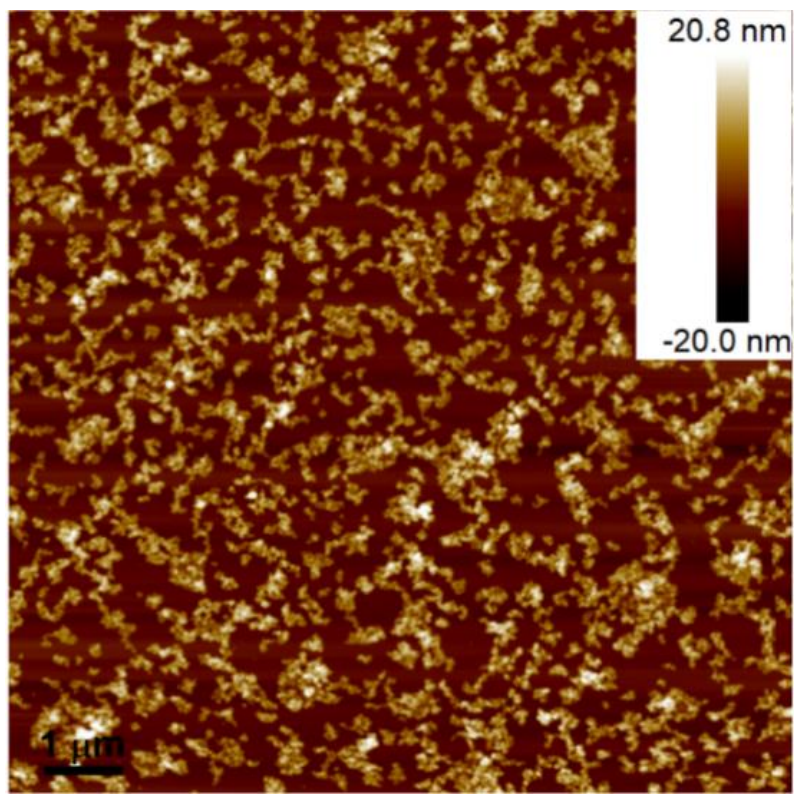

Figure S26. AFM image of Pman-PVEA in PBS buffer solution.
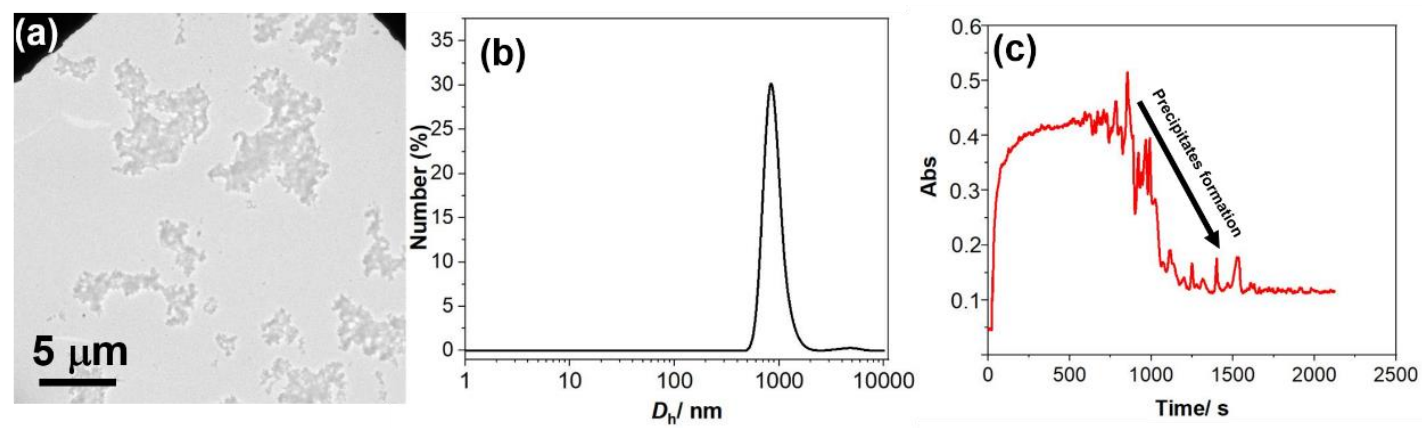

Figure S27. Characterization of Pman-PVEA $(0.2 \mathrm{mg} / \mathrm{mL})$ with ConA $(0.5 \mathrm{mg} / \mathrm{mL})$ : (a) TEM image, (b) DLS analysis and (c) real-time recording of UV absorption at 450 nm after adding ConA into Pman-PVEA aqueous solution. 


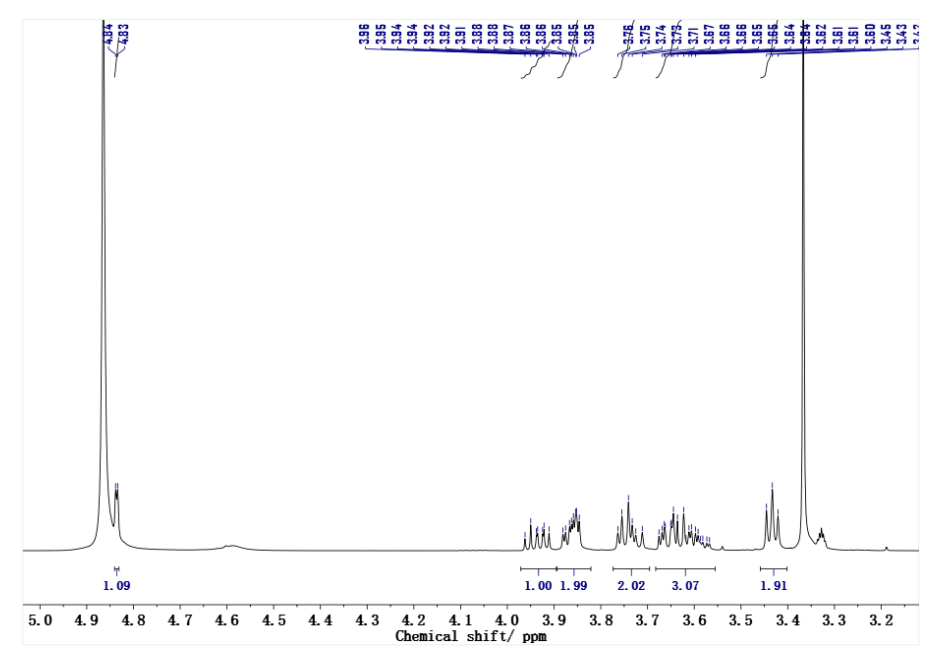

Figure S28. ${ }^{1} \mathrm{H}$ NMR spectrum of Man-N $\mathbf{N}_{3}$ in $\mathrm{CD}_{3} \mathrm{OD}$.
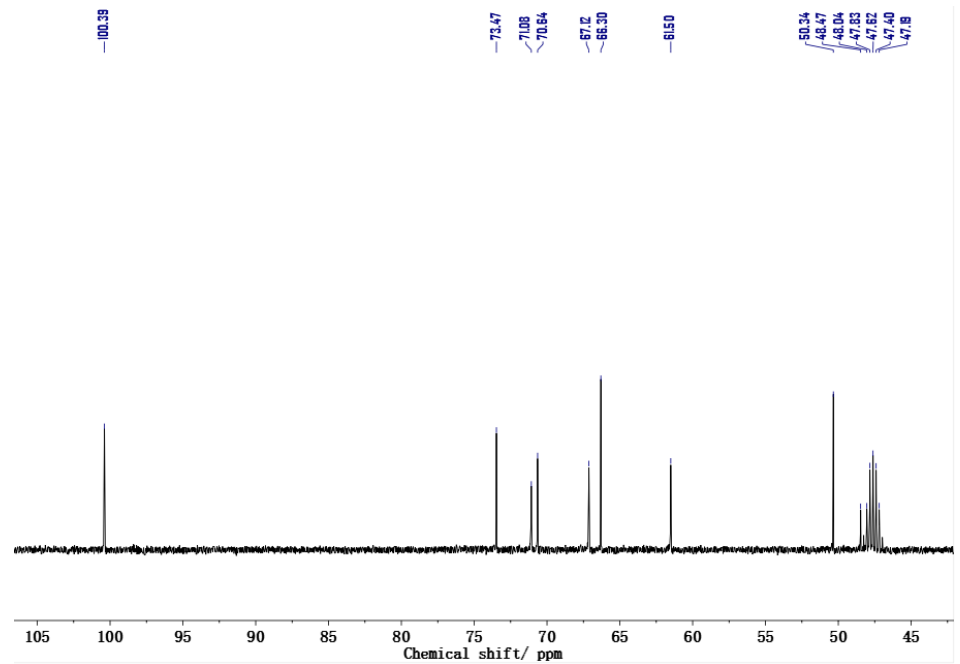

Figure S29. ${ }^{13} \mathrm{C}$ NMR spectrum of $\mathrm{Man}-\mathrm{N}_{3}$ in $\mathrm{CD}_{3} \mathrm{OD}$. 


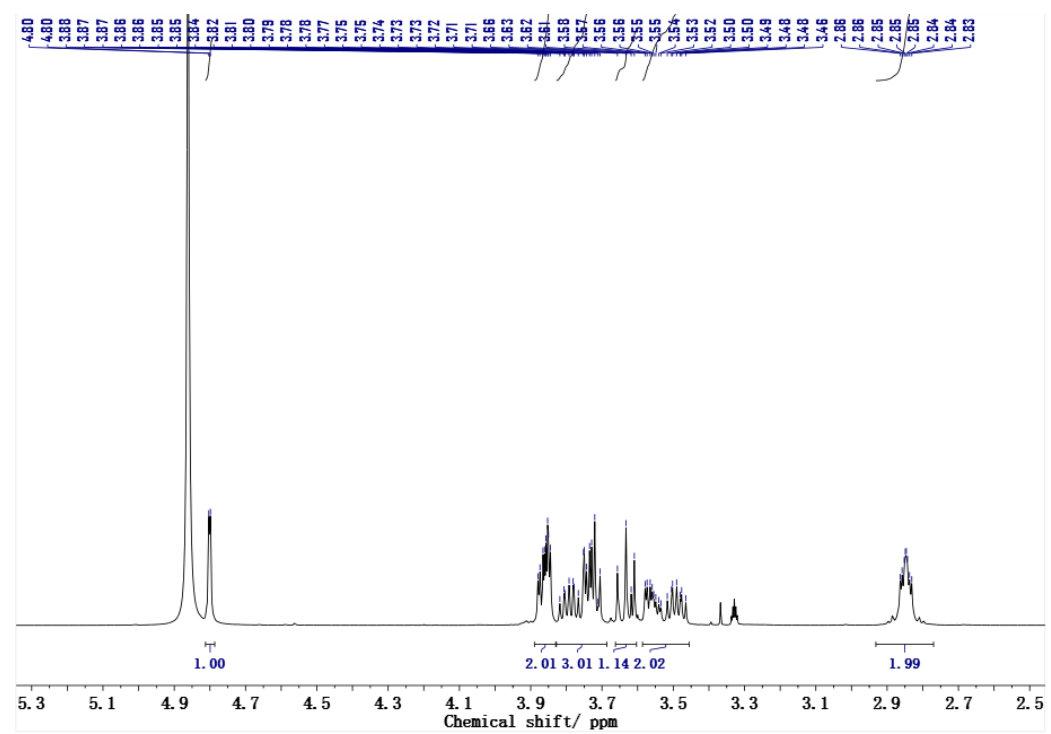

Figure S30. ${ }^{1} \mathrm{H}$ NMR spectrum of Man-NH2 in $\mathrm{CD}_{3} \mathrm{OD}$.

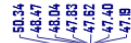

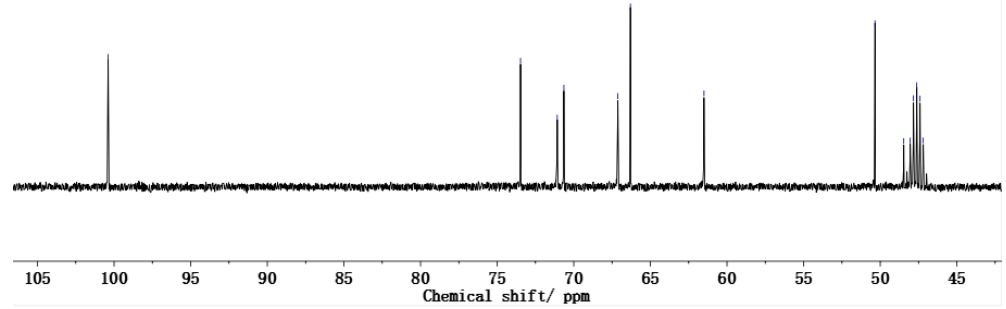

Figure S31. ${ }^{13} \mathrm{C}$ NMR spectrum of Man- $\mathbf{N H}_{2}$ in $\mathrm{CD}_{3} \mathrm{OD}$.
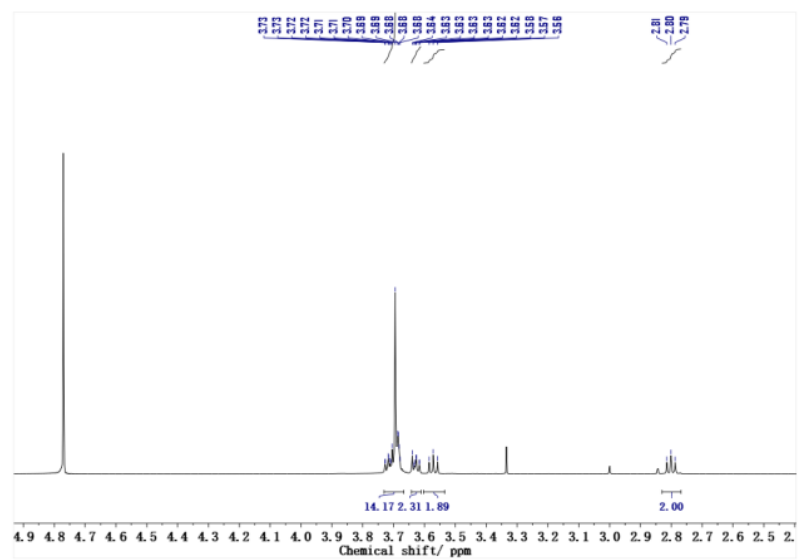

Figure S32. ${ }^{1} \mathrm{H}$ NMR spectrum of $\mathbf{E G}_{\mathbf{5}} \mathbf{N H}_{2}$ in $\mathrm{CD}_{3} \mathrm{OD}$. 


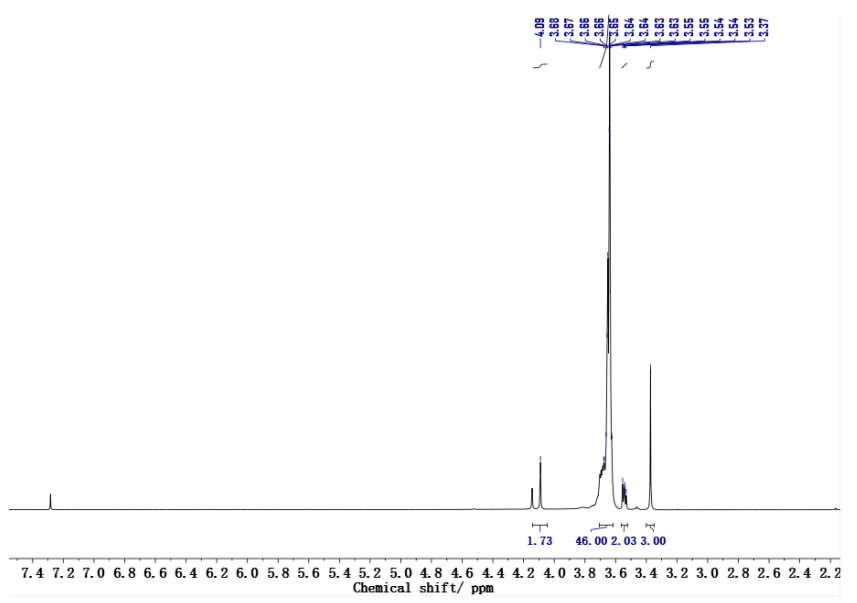

Figure S33. ${ }^{1} \mathrm{H}$ NMR spectrum of $\mathbf{E G N H N H} 2$ in $\mathrm{CDCl}_{3}$.

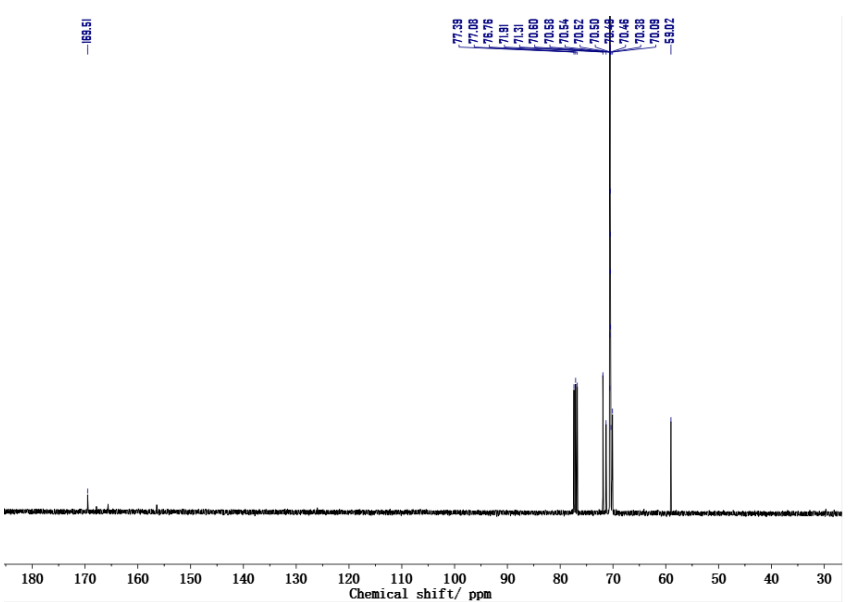

Figure S34. ${ }^{13} \mathrm{C}$ NMR spectrum of EGNHNH2 in $\mathrm{CDCl}_{3}$.

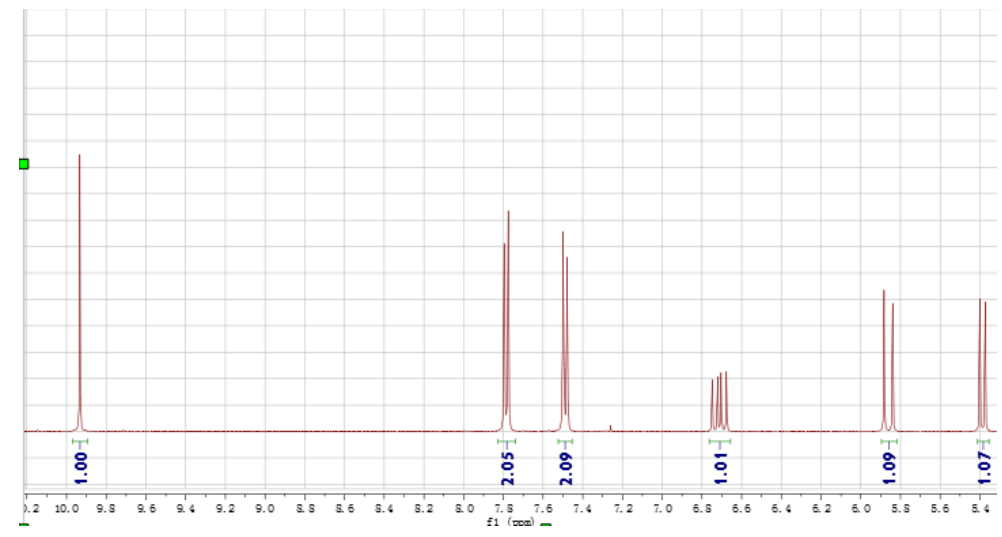

Figure S35. ${ }^{1} \mathrm{H}$ NMR spectrum of VBA in $\mathrm{CDCl}_{3}$. 

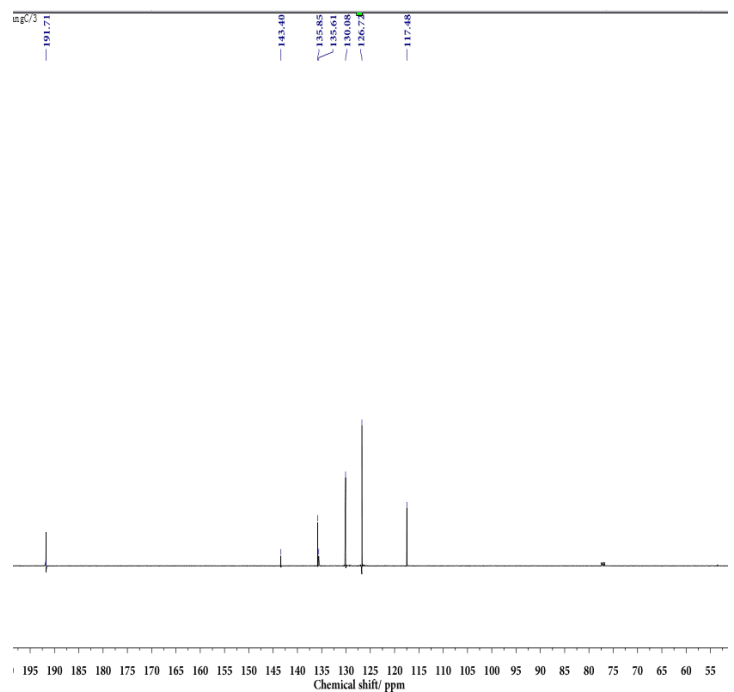

Figure S36. ${ }^{13} \mathrm{C}$ NMR spectrum of VBA in $\mathrm{CDCl}_{3}$.

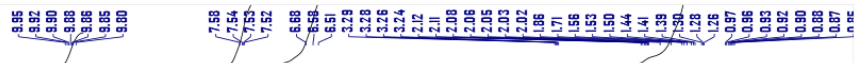

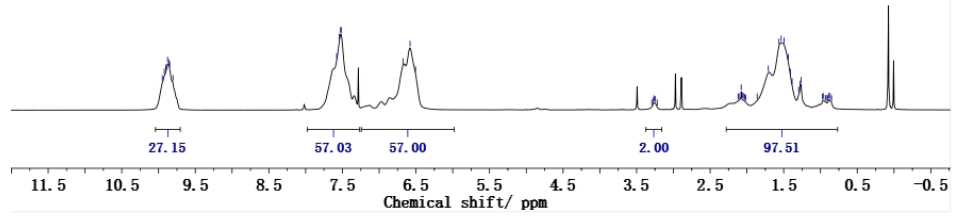

Figure S37. ${ }^{1} \mathrm{H}$ NMR spectrum of PVBA in $\mathrm{CDCl}_{3}$. 


\section{References}

1. Yang, G.; Kochovski, Z.; Ji, Z.; Lu, Y.; Chen, G.; Jiang, M. Three-dimensional protein assemblies directed by orthogonal non-covalent interactions. Chem. Commun. 2016, 52, 9687-9690.

2. Yang, G.; Ding, H. M.; Kochovski, Z.; Hu, R. T.; Lu, Y.; Ma, Y. Q.; Chen, G.; Jiang, M. Highly ordered self-assembly of native proteins into $1 \mathrm{~d}, 2 \mathrm{~d}$ and $3 \mathrm{~d}$ structures modulated by a tether length of inducing ligands. Angew. Chem. Int. Ed. 2017,56, 10691-10695.

3. Zhao, Y.; Zhang, Y. F.; Wang, C. C.; Chen, G.; Jiang, M. The Role of Protecting Groups in Synthesis and Self-Assembly of Glycopolymers. Biomacromolecules 2017, $18,568-575$

4. He, L.; Jiang, Y.; Tu, C.; Li, G.; Zhu, B.; Jin, C.; Zhu, Q. Yan. D. Y.; Zhu, X. . Selfassembled encapsulation systems with $\mathrm{pH}$ tunable release property based on reversible covalent bond. Chem. Commun. 2010, 46, 7569-7571.

5. Dan, M.; Su, Y.; Xiao, X.; Li, S.; Zhang, W. A new family of thermo-responsive polymers based on poly [ $N$-(4-vinylbenzyl)- $N, N$-dialkylamine]. Macromolecules 2013, $46,3137-3146$. 